\title{
Migration and degradation of swine farm tetracyclines at the river catchment scale: Can the multi-pond system mitigate pollution risk to receiving rivers? ${ }^{\text {th }}$
}

\author{
Qiuwen Chen ${ }^{\text {a, }}{ }^{*}$, Xiao Guo ${ }^{\text {b }}$, Guofen Hua ${ }^{\text {a }}$, Guoliang Li ${ }^{b}$, Ranran Feng ${ }^{\text {a }}$, Xiaoli Liu ${ }^{\text {b }}$ \\ a Center for Eco-Environmental Research, Nanjing Hydraulic Research Institute, Nanjing 210029, China \\ ${ }^{\mathrm{b}}$ Research Center for Eco-Environmental Sciences, Chinese Academy of Sciences, Beijing 100085, China
}

\section{A R T I C L E I N F O}

\section{Article history:}

Received 15 July 2016

Received in revised form

31 October 2016

Accepted 1 November 2016

Available online 10 November 2016

\section{Keywords:}

Tetracycline antibiotics

Migration path

Decay behavior

Degradation products

Natural interception

\begin{abstract}
A B S T R A C T
The study investigated the degradation behaviors of swine farm tetracyclines (TCs) at a catchment scale and explored whether multi-pond systems could be beneficial to the interception of TCs so as to reduce the pollution risk to receiving rivers. The occurrence and migration of 12 kinds of tetracycline antibiotics, including their degradation products, were studied in four swine farms of the Meijiang River basin in China. The migration paths of the TCs were examined through sampling and analyzing the soil and/or sediment at different points along the swine wastewater outlet, which included sewer, sewage pond, mixed-canal (stream and sewage), farmland (paddy and upland soil) and finally the river. TC concentrations of all collected samples were obtained by solid phase extraction followed by measurement with high-performance liquid chromatography tandem mass spectrometry. The results showed that sediment TC concentrations varied greatly in different swine farms, from $\mathrm{mg} \cdot \mathrm{kg}^{-1}$ to $\mu \mathrm{g} \cdot \mathrm{kg}^{-1} \mathrm{levels}$. TCs had different decay patterns along different migration paths, such that TCs decayed exponentially in paddy soil, while linearly in sewer and mixed canal. The concentrations of TCs and their degradation products decreased in the order: sewer sediment $>$ sewage pond sediment $>$ mixed-canal sediment $>$ paddy soil > upland soil, indicating that TCs tend to be more easily intercepted and accumulated in watersediment systems such as ponds. Therefore, the multi-pond system could be an effective way to prevent TCs from migrating into rivers. These results provided essential information for contamination control of antibiotics in aquatic environments.
\end{abstract}

(C) 2016 Elsevier Ltd. All rights reserved.

\section{Introduction}

Antibiotics are indispensable for maintaining both human and animal health through treatment of various diseases (Luo et al, 2011), and are also used as growth promoters to enhance development and improve feed efficiency in livestock farming (Hu et al., 2010). However, many antibiotics are excreted in unchanged form due to poor gut absorption or incomplete metabolism, and may even generate toxic metabolites (McArdell et al., 2003; Sarmah et al., 2006). Therefore, despite their beneficial attributes, antibiotics are increasingly recognized as potential emerging pollutants, which can disrupt the ecological balance in the environment (Zheng, 2013). Tetracyclines (TCs), a class of veterinary antibiotics,

\footnotetext{
* This paper has been recommended for acceptance by Klaus Kummerer

* Corresponding author. Hujuguan 34, Nanjing 210029, China.

E-mail address: qwchen@nhri.cn (Q. Chen).
}

are widely used in livestock and poultry farming due to their low cost, ease of use and relatively minor side effects (Wei et al., 2010).

Previous studies reported that antibiotic concentrations in animal manure and wastewater in poultry farms were at $\mathrm{mg} \cdot \mathrm{kg}^{-1}$ and $\mu \mathrm{g} \cdot \mathrm{L}^{-1}$ levels, respectively (Zhang et al., 2005; Liu et al., 2008). The concentration ranges in manure samples from European countries were also at the $\mathrm{mg} \cdot \mathrm{kg}^{-1}$ level, e.g. $0.1-46.0,0.1-4.0$ and $0.1-24.4 \mathrm{mg} \mathrm{kg}^{-1}$ in Austria (Martinez-Carballo et al., 2007), Germany (Hamscher et al., 2002) and Denmark (Jacobsen and HallingSorensen, 2006), respectively. The concentrations of antibiotics in Chinese farm wastewater have been mostly found to be at the $\mu \mathrm{g} \cdot \mathrm{L}^{-1}$ level, e.g. the maximum concentrations of $0.97,12.07,13.65$ and $3.64 \mu \mathrm{g} \mathrm{L}^{-1}$ for TC, Oxytetracycline (OTC), chlortetracycline (CTC) and doxycycline (DXC), respectively, reported in the study of Chen et al. (2010).

Zhu et al. (2001) and Chen et al. (2010) reported that animal manure with high antibiotic content and large volumes of washing wastewater, especially from large-scale farms, caused considerable 
antibiotic pollution to the surrounding environment. Several other studies have also reported on antibiotic-contaminated soil (Aust et al., 2008; Li et al., 2011; Shi et al., 2012). Hamscher et al. (2000) reported maximum residue levels of OTC and CTC as high as 32.3 and $26.4 \mathrm{mg} \mathrm{kg}^{-1}$ in topsoil fertilized with animal waste over a long period of time. Zhang et al. (2008) found that residue levels of TC, OTC and CTC in agricultural soil treated with manure were 13,38 and 12 times higher, respectively, than those in soil without manure treatment. These antibiotic residues can further be transferred through the food chain. Hu et al. (2010) demonstrated that antibiotics could be taken up through water transport and passive absorption in vegetables. Antibiotics in soil can be further transported into rivers through scouring by surface runoff, infiltration and migration in the unsaturated water zone (He et al., 2011). Additionally, wastewater from livestock, for example, is typically discharged directly into nearby streams along with sewage. These two sources (i.e., wastewater and sewage) also contaminate receiving waters with antibiotics, which can be further adsorbed into sediment by Van der Waals attraction, hydrogen bonding and hydrophobic partitioning (Tolls, 2001). In river ecosystems, sediment is the carrier, home and accumulation reservoir of TC migration and transformation in the water/sediment system. Although the half-lives of most antibiotics are quite short, they can cause ecological impact, as they enter the aquatic environment continually due to constant use and production, and can even enter the human body through the food chain, which is a serious threat to human health (Zhou et al., 2013).

To date, most studies on antibiotic residues have centered on either agricultural soil to which antibiotic-rich animal manure has been applied, or on rivers polluted by urban sewage treatment plant effluents (He et al., 2011; Li et al., 2011). The migration and transformation of antibiotics at the catchment scale have received limited attention (Aust et al., 2008; Kim et al., 2010), especially the efficacy of multi-pond systems in intercepting antibiotics such as tetracyclines from intensive swine farms. The objective of this study was to: (1) reveal the migration path and degradation behavior of swine farm tetracyclines at a river catchment scale; (2) investigate if the multi-pond system could mitigate TC pollution risk to receiving rivers.

\section{Materials and methods}

\subsection{Sampling area and collection}

The Meijiang River catchment (Fig. 1), located at east longitude $115^{\circ} 22^{\prime}-116^{\circ} 38^{\prime}$, north latitude $25^{\circ} 58^{\prime}-27^{\circ} 09^{\prime}$, is an important section of the Gongshui River. The catchment covers an area of $1405 \mathrm{~km}^{2}$ and is an intensive farming area, according to a farm scale investigation in 2014 (National Bureau of Statistics, 2014). Its annual average temperature and multi-year average precipitation are $19.3^{\circ} \mathrm{C}$ and $1665.0 \mathrm{~mm}$, respectively. Rainfall distribution in this catchment declines gradually from north to south, and mean annual average runoff is 6.73 billion $\mathrm{m}^{3}$. Rainstorm floods tend to occur during March to June, with most concentrated in June. The Meijiang River catchment has a landscape of multi-pond systems, which is are common and widespread in south China (Yin et al., 1993).

Samples were collected from four typical swine farms, viz. Swine Farms 1, 2, 3 and 4 (Fig. 1), where the modes of antibiotic migration into the surrounding environment differed. The pig herd numbers in Swine Farms 1, 2, 3, and 4 were 100, 500, 120 and 500, respectively. Fig. 2 shows the different sewage migration paths of the four farms in detail. The migration paths in Swine Farms 1 and 2 were single, straight routes, with total lengths of $1000 \mathrm{~m}$ and 200 m, respectively. In contrast, Swine Farms 3 and 4 each had two migration paths. For Swine Farm 3, one path was a sewer, named Swine Farm 3(s), and the other passed through $385 \mathrm{~m}$ of paddy field, named Swine Farm 3(p). For Swine Farm 4, there was no direct drainage flow from the farm itself to P4-2 and P4-4 (defined as sample points 2 and 4 of Swine Farm 4). However, since both P42 and P4-4 were located in relatively low terrain, they could still be contaminated by rainfall runoff, as surface runoff is an important transport route of veterinary antibiotic residue (Kay et al., 2005; Kim et al., 2010). At each sampling point along the migration paths of each farm, $50 \mathrm{~g}$ of sediment or soil was collected with three duplicates, sealed in foil and placed into polyethylene (PE) bags in the field. The samples were then cooled at $-20{ }^{\circ} \mathrm{C}$ in a portable refrigerator before analysis (Karci and Balcioglu, 2009). The detailed procedure for collecting and treating water samples prior to analysis was as follows: $100 \mathrm{ml}$ water samples were collected at each point separately into brown glass sampling bottles, which had been previously washed with methanol and rinsed with pure water. The water samples were taken back to the lab as soon as possible and then were filtered with $0.45 \mu \mathrm{m}$ glass fiber filters to remove suspended particulate matter. Finally, the water samples were stored in a refrigerator at $4{ }^{\circ} \mathrm{C}$ and their pretreatments were completed within $48 \mathrm{~h}$.

\subsection{Sample extraction and purification}

Results of an investigation of antibiotic utilization in the swine farms in the Meijiang catchment, TC antibiotics are widely used, including tetracycline, oxytetracycline, doxycycline, etc., but no TC degradation products are directly used. In order to make the migration and degradation of TCs clear, eleven TCs were analyzed in this study, including TC and its degradation products (epitetracycline (ETC), epianhydrotetracycline (EATC), OTC and its degradation products (epioxytetracycline (EOTC), $\alpha$-apo-oxytetracycline $(\alpha-$ OTC) and $\beta$-apo-oxytetracycline ( $\beta$-OTC)), methacycline (MTC), DXC, and CTC and its degradation product isochlortetracycline (ICTC). All the TC analytical standards were purchsed from the United States Pharmacopeia.

Extraction and cleanup of the soil and sediment samples for TCs were performed as per Karci and Balcioglu (2009), with some modification. Briefly, the wet samples were lyophilized, ground to fine particles and sieved (100 mesh). One gram of each sample was then transferred to a centrifuge tube, followed by the addition of $100 \mu \mathrm{L}$ of demeclocycline (internal standard DMC, $1 \mathrm{mg} \mathrm{L}^{-1}$ ) solution. Next, $8 \mathrm{~mL}$ of extraction buffer $\mathrm{Mg}\left(\mathrm{NO}_{3}\right)_{2}$ (29\%(w/v); $\mathrm{pH}=8.1$ ) was added, after which the tubes were vortexed for $1 \mathrm{~min}$, ultrasonicated for $30 \mathrm{~min}$ and centrifuged at $3500 \mathrm{rpm}$ for $10 \mathrm{~min}$ at $10{ }^{\circ} \mathrm{C}$, with the supernatant finally decanted into $500 \mathrm{~mL}$ glass bottles. The extraction process was repeated two more times. The supernatant was further diluted using ultrapure water to a final volume of $400 \mathrm{~mL}$, followed by the addition of $0.8 \mathrm{~g} \mathrm{Na}_{2}$ EDTA. The $\mathrm{pH}$ of the mixture was adjusted to 3.0 by adding $\mathrm{HCl}$. Oasis hydrophilic-lipophilic balance (HLB) cartridges $(6 \mathrm{~mL} / 500 \mathrm{mg}$, Waters, Watford, UK), which were used for solid phase extraction, were preconditioned sequentially with $6 \mathrm{~mL}$ of methanol, $6 \mathrm{~mL}$ of ultrapure water and $6 \mathrm{~mL}$ of $\mathrm{Na}_{2}$ EDTA buffer $\left(0.01 \mathrm{~mol} \mathrm{~L}^{-1}\right.$, $\mathrm{pH}=3.0$ ) before the samples were extracted. The supernatant was passed through the cartridges at a loading rate of $5 \mathrm{~mL} / \mathrm{min}$. After the entire sample was loaded, the HLB cartridges were then rinsed with $10 \mathrm{~mL}$ of ultrapure water and completely dried with nitrogen gas. The HLB cartridges were eluted twice with $4 \mathrm{~mL}$ of methanol, and the analytes were reduced to $20 \mu \mathrm{L}$ under nitrogen gas flow and dissolved in a methanol-water-formic acid (49.5:49.5:1, v/v/v) mixture to a final volume of $1 \mathrm{~mL}$, then were passed through $0.22 \mu \mathrm{m}$ glass filters into $1.5 \mathrm{~mL}$ brown glass vials before chromatographic analysis. The HLB SPE extraction procedure was the 


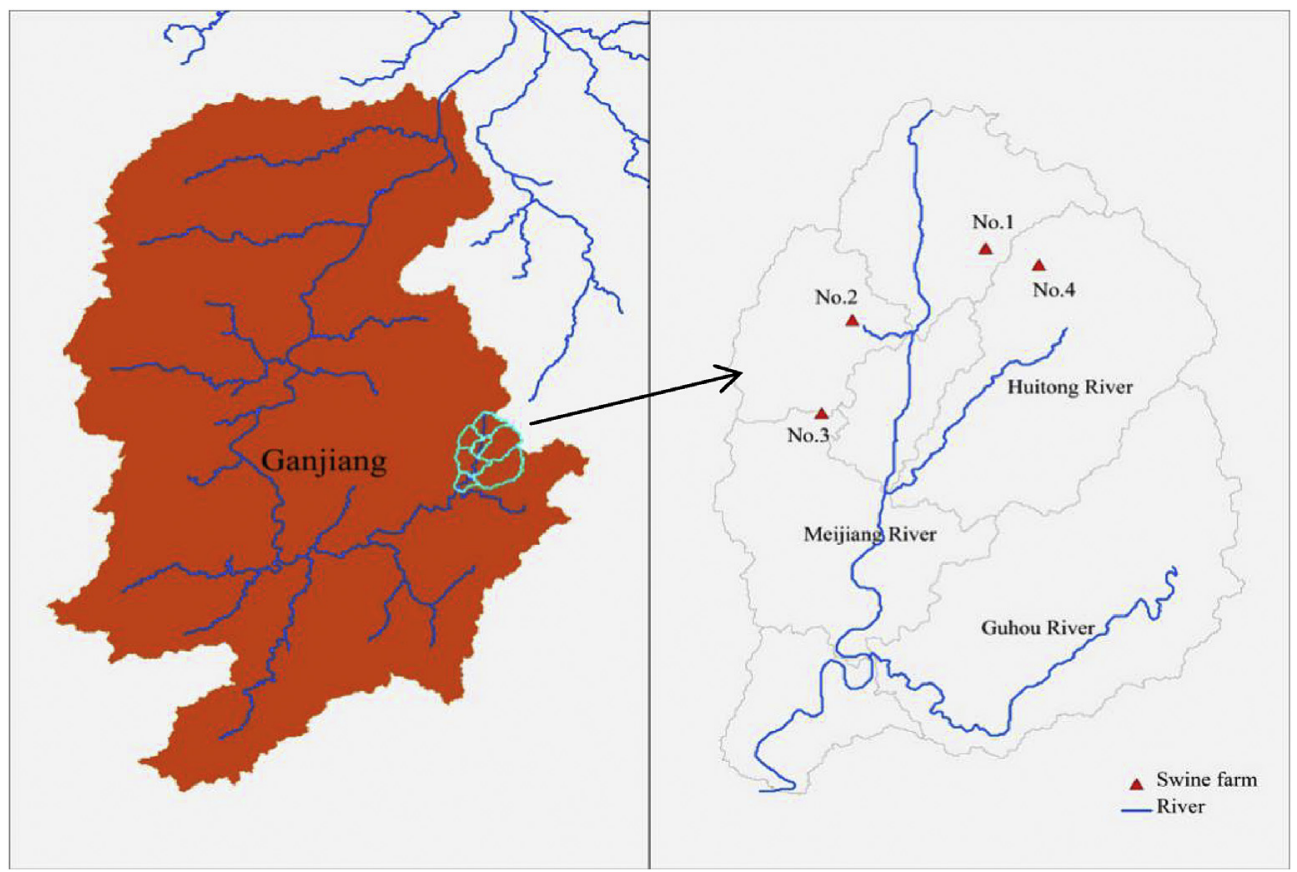

Fig. 1. Sampling area locations and sampling points of swine farms.

same for the water samples.

\subsection{Instrument analysis and quality control}

Chromatographic separation of the TCs was performed on an Ultra Performance LC/MS system (Waters Corp., Milford MA) equipped with an ACQUITY UPLC BEH ${ }^{\mathrm{TM}} \mathrm{C}_{18}$ column $(1.7 \mu \mathrm{m}$, $100 \mathrm{~mm} \times 2.1 \mathrm{~mm}$, Waters Corp., USA) using binary gradient mobile phases and DMC as the internal standard. The correlation coefficients $\left(r^{2}\right)$ of the calibration curve were higher than 0.99 . The concentrations of TCs were calculated using the standard sample test curve. Mass spectrometry (MS) parameters for all TCs measured, including parent ion $(\mathrm{m} / \mathrm{z})$, daughter ion $(\mathrm{m} / \mathrm{z})$, cone voltage $(\mathrm{V})$ and fragmentor voltage $(\mathrm{V})$, are shown in Table 1.

Formic acid (v/v:0.1\%) was used as mobile phase A and "CAN" as mobile phase $B$. The flow rate $\left(0.3 \mathrm{ml} \mathrm{min}^{-1}\right)$ and column temperature $\left(30^{\circ} \mathrm{C}\right)$ were optimized based on the separation and signal intensities of the analytes. The initial mobile phase proportion was
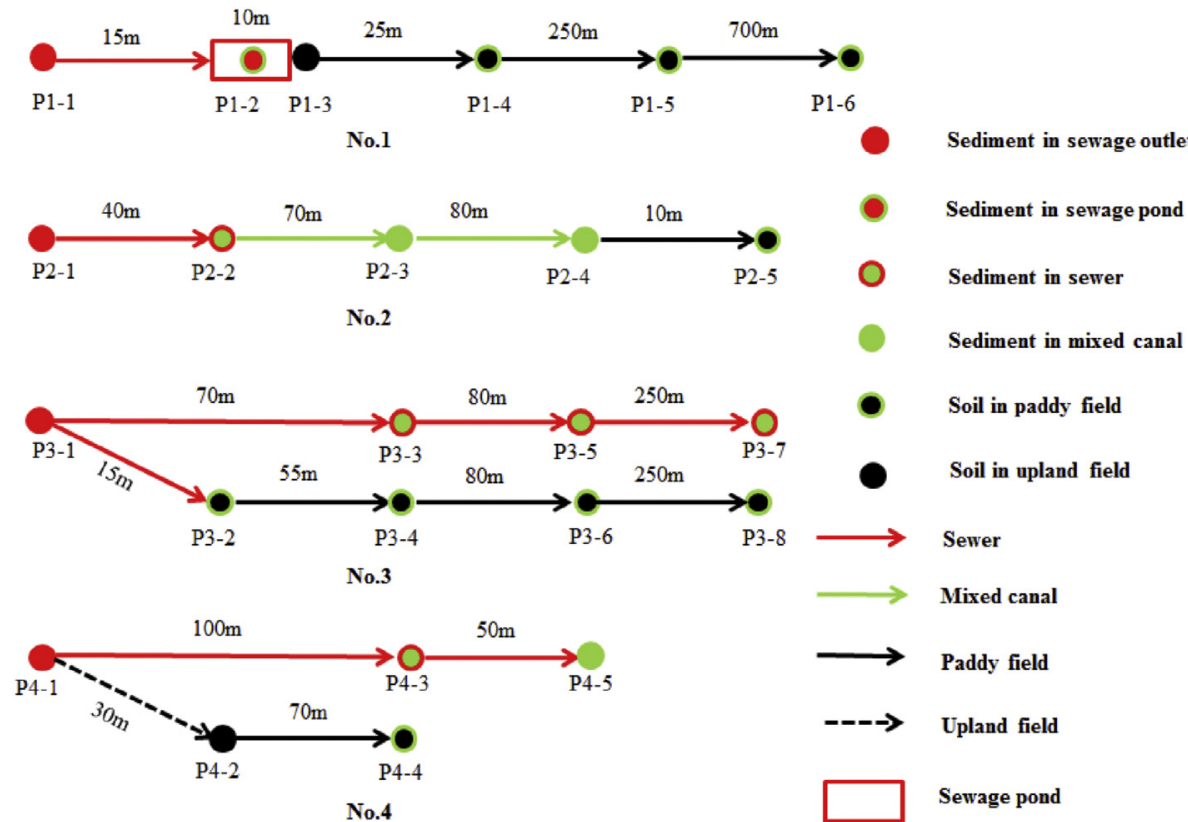

Fig. 2. Migration paths of sewage from the four typical swine farms and sampling points along the paths. 
Table 1

MS parameters for measuring TCs.

\begin{tabular}{lllll}
\hline & $\begin{array}{l}\text { Parent ion } \\
(\mathrm{m} / \mathrm{z})\end{array}$ & $\begin{array}{l}\text { Daughter } \\
\text { ion }(\mathrm{m} / \mathrm{z})\end{array}$ & $\begin{array}{l}\text { Cone } \\
\text { voltage }(\mathrm{V})\end{array}$ & $\begin{array}{l}\text { Fragmentor } \\
\text { voltage }(\mathrm{V})\end{array}$ \\
\hline TC & 445.5 & 153.9 & 28 & 26 \\
& 445.5 & 410.3 & 28 & 20 \\
ETC & 445.5 & 410.4 & 28 & 19 \\
& 445.5 & 410.4 & 28 & 19 \\
EATC & 427.4 & 154.0 & 31 & 16 \\
& 427.4 & 410.5 & 31 & 16 \\
OTC & 461.5 & 426.4 & 22 & 19 \\
EOTC & 461.5 & 443.5 & 22 & 16 \\
$\alpha-O T C$ & 443.5 & 408.4 & 31 & 25 \\
& 443.5 & 426.4 & 31 & 16 \\
$\beta-O T C$ & 443.2 & 407.5 & 31 & 25 \\
& 443.2 & 426.5 & 31 & 16 \\
MTC & 443.5 & 201.0 & 28 & 31 \\
& 443.5 & 426 & 28 & 16 \\
DXC & 445.5 & 153.9 & 28 & 16 \\
& 445.5 & 428.4 & 28 & 22 \\
CTC & 479.6 & 444.3 & 34 & 15 \\
& 479.6 & 462.4 & 34 & 40 \\
ICTC & 479.3 & 197 & 34 & 15 \\
& 479.3 & 462.4 & 34 & 19 \\
DMC & 465.5 & 430.3 & 34 & 34 \\
& 465.5 & 448.4 & 34 & \\
\hline
\end{tabular}

95\% (A) and 5\% (B). Mobile phase A was linearly decreased to $83 \%$ within the first $5 \mathrm{~min}$ and then to $70 \%$ over $1 \mathrm{~min}$, followed by a rapid decrease to $15 \%$ within $4 \mathrm{~min}$ and then to $0 \%$ over $1 \mathrm{~min}$. Finally, mobile phase A was increased rapidly to the initial percentage (95\%) over $0.5 \mathrm{~min}$ for a total run time of $11.5 \mathrm{~min}$. MassLynx 4.1 software was used to collect and analyze the data. Recovery tests were performed by spiking the samples (water, sediment and soil samples from study sites) with $100 \mu \mathrm{L}$ of DMC ( $1 \mathrm{mg} \mathrm{L}^{-1}$ ), which were then compared with the controls with no added DMC. The recoveries and relative standard deviation (RSD) of the 12 TCs in different media are shown in Table 2.

\section{Results}

\subsection{TC concentrations of wastewater in the swine farm outlets}

The TC concentrations of the wastewater in the outlets of the four swine farms in Meijiang river catchment are shown in Table 3. Among the four wastewater samples, samples 1, 2 and 4 were wastewater from pigsty cleaning, while sample 3 was a mixture of pigsty cleaning wastewater and concentrated pig

Table 2

Recovery and RSD (\%) of 12 tetracycline antibiotics.

\begin{tabular}{|c|c|c|c|c|c|c|c|}
\hline \multirow[t]{2}{*}{ TCs } & & \multicolumn{2}{|l|}{ In water } & \multicolumn{2}{|c|}{ In sediment } & \multicolumn{2}{|l|}{ In soil } \\
\hline & & Recovery & RSD & Recovery & RSD & Recovery & RSD \\
\hline \multirow[t]{3}{*}{ TC } & TC & 74.00 & 22.19 & 67.98 & 12.43 & 72.35 & 11.01 \\
\hline & ETC & 66.25 & 20.87 & 67.12 & 16.44 & 68.25 & 15.23 \\
\hline & EATC & 52.50 & 6.87 & 39.87 & 8.58 & 51.32 & 8.77 \\
\hline \multirow[t]{4}{*}{ OTC } & OTC & 67.00 & 21.44 & 75.53 & 18.79 & 78.95 & 6.17 \\
\hline & EOTC & 83.00 & 20.36 & 87.40 & 12.05 & 89.20 & 13.28 \\
\hline & $\alpha$-OTC & 57.25 & 7.01 & 40.08 & 7.65 & 54.33 & 5.21 \\
\hline & $\beta$-OTC & 76.50 & 18.45 & 62.92 & 7.78 & 79.41 & 7.17 \\
\hline \multirow[t]{2}{*}{ СТC } & CTC & 75.00 & 18.29 & 55.87 & 7.71 & 77.48 & 16.35 \\
\hline & ICTC & 81.75 & 13.39 & 94.25 & 6.63 & 85.41 & 12.07 \\
\hline MTC & & 67.75 & 15.22 & 61.82 & 7.15 & 78.36 & 9.62 \\
\hline DXC & & 71.75 & 17.89 & 65.60 & 9.45 & 76.35 & 20.01 \\
\hline DMC & & 95.50 & 15.04 & 75.69 & 19.47 & 86.37 & 14.62 \\
\hline
\end{tabular}

urine. Thus, it was clearly observed that the concentration of TCs from the outlet of Swine Farm 3 was the highest, because the pigsty cleaning wastewater was a dilution of pig urine. In addition, TC, OTC, DXC and CTC were detected, and their maximum concentrations were $1.14,129.14,4.29$ and $129.14 \mathrm{mg} \mathrm{L}^{-1}$, respectively. MTC was not detected, which might be because MTC was not used in the Meijiang basin based on our in-situ investigation. OTC had the highest detection rate of up to $100.00 \%$ and its concentration was much higher than other kinds of TC. The CTC detection rate was less than $25 \%$ since it is rapidly degraded to isochlortetracycline and epi-isochlortetracycline, but the maximum concentration was higher than that of TC and DXC. Two degradation products ETC and EATC of TC, and one degradation product ICTC of CTC were detected, and the highest ICTC concentration was $30.84 \mathrm{mgL}^{-1}$, while the EATC concentration was $0.44 \mathrm{mgL}^{-1}$. EOTC and $\alpha$-OTC, which are the degradation products of OTC, were detected, while $\beta$-OTC was not detected. This may be because EOTC and $\alpha$-OTC were not directly used in the farms and may come from animal degradation in the process of digestion and excretion. $\beta$-OTC was not detected, so its detection in other samples in the river basin must be derived from OTC degradation in the migration process.

\subsection{Migration and transformation of TCs from the four farms}

For Swine Farm 1, the variations in concentrations of TC, OTC and their degradation products as well as DTX and CTC in sediment or soil are given in Table 4. Most tested TCs were detected in the swine farm samples and also in the sewage outlet sediment. The highest concentration was $25.79 \mathrm{mg} \mathrm{kg}^{-1}$ for CTC, $1.12 \mathrm{mg} \mathrm{kg}^{-1}$ for TC and $9.11 \mathrm{mg} \mathrm{kg}^{-1}$ for ICTC. The lowest concentration was $0.03 \mathrm{mg} \mathrm{kg}^{-1}$ for $\alpha$-OTC, with $\beta$-OTC, MTC and DXC not detected. The TCs detected at P1-2 were different from those detected at P11. For instance, only DXC was not detected at P1-1, while at P1-2 DXC, EOTC (degradation product of OTC), $\beta$-OTC and MTC were also not detected. At P1-1, the concentrations of detected TCs ranged from 0.03 to $2.86 \mathrm{mg} \mathrm{kg}^{-1}$, and the concentrations of TC, ICTC and CTC were higher than those at P1-2. However, the concentration of OTC at P1-2 $\left(0.75 \mathrm{mg} \mathrm{kg}^{-1}\right)$ was higher than that found at P1-1, which was a different pattern from that observed for TC and CTC.

At the P1-3 sewage pond exit, small changes were observed for the detected species (i.e., no ETC or $\alpha$-OTC was detected, unlike P12 ), indicating that degradation occurred along the migration path. The other TCs were detected in the concentration range of $1.21-43.77 \mu \mathrm{g} \mathrm{kg}^{-1}$. Although greatly decreased from the values at P1-2, P1-3 concentrations of the parent TCs (i.e. TC, OTC and DXC) exceeded the $100 \mu \mathrm{g} \mathrm{kg}^{-1}$ threshold set by the Veterinary International Committee on Harmonization (VICH) based on the ecotoxicity of antibiotic compounds towards organisms (Qiao et al., 2012).

The detected antibiotics at P1-4 included ICTC, OTC, $\alpha$-OTC, $\beta$ OTC, DXC and CTC, with concentrations ranging from 0.86 to $59.65 \mu \mathrm{g} \mathrm{kg}^{-1}$, and a $\Sigma$ TCs concentration of $94.67 \mu \mathrm{g} \mathrm{kg}^{-1}$. The concentrations of most TCs at P1-4 were lower than those at P1-3, which was likely due to P1-4 being $25 \mathrm{~m}$ further along the migration path. Furthermore, although P1-5 and P1-6 were $300 \mathrm{~m}$ and $1000 \mathrm{~m}$ from the farm outlet, respectively, they were still contaminated with EATC, ICTC, OTC, $\beta$-OTC, DXC and CTC at concentrations in the range of $0.86-4.06$ and $1.92-27.13 \mu \mathrm{g} \mathrm{kg}^{-1}$. Among the detected antibiotics at P1-5, all concentrations were lower than those found at P1-4, with the exception of EATC. In general, the concentrations of OTC, DXC and CTC decreased with distance along the migration path.

At Swine Farm 2, the variations in concentrations of TC, OTC and 
Table 3

Concentrations $\left(\mu \mathrm{g} \mathrm{L}^{-1}\right)$ of tetracycline antibiotics detected in the wastewater samples.

\begin{tabular}{|c|c|c|c|c|c|}
\hline TCs & & Farm 1 & Farm 2 & Farm 3 & Farm 4 \\
\hline \multirow[t]{3}{*}{ TC } & $\mathrm{TC}$ & $1.14 \pm 0.15$ & $1.09 \pm 0.12$ & $0.74 \pm 0.08$ & ND \\
\hline & ETC & $0.54 \pm 0.02$ & $0.28 \pm 0.03$ & $1.41 \pm 0.12$ & $0.31 \pm 0.04$ \\
\hline & EATC & $0.25 \pm 0.01$ & ND & $0.44 \pm 0.03$ & ND \\
\hline \multirow[t]{4}{*}{ OTC } & OTC & $5.23 \pm 0.62$ & $0.88 \pm 0.06$ & $129.14 \pm 15.32$ & $5.68 \pm 0.42$ \\
\hline & EOTC & $0.38 \pm 0.02$ & ND & $16.86 \pm 1.27$ & ND \\
\hline & $\alpha$-OTC & ND & ND & $4.81 \pm 0.36$ & ND \\
\hline & $\beta$-ОTC & ND & ND & ND & ND \\
\hline \multirow[t]{2}{*}{ CTC } & CTC & $15.28 \pm 1.62$ & ND & ND & ND \\
\hline & ICTC & $30.84 \pm 4.23$ & $4.65 \pm 0.32$ & $1.29 \pm 0.14$ & $0.5 \pm 0.06$ \\
\hline MTC & & ND & ND & ND & ND \\
\hline DXC & & $0.13 \pm 0.01$ & ND & $4.29 \pm 0.28$ & $3.37 \pm 0.34$ \\
\hline
\end{tabular}

ND: not detected.

Table 4

Concentrations of TCs along the migration paths at Swine Farm 1.

\begin{tabular}{|c|c|c|c|c|c|c|}
\hline & P1-1 (mg kg-1) & P1-2 $\left(\mathrm{mg} \mathrm{kg}^{-1}\right)$ & $\mathrm{P} 1-3\left(\mathrm{mg} \mathrm{kg}^{-1}\right)$ & $\mathrm{P} 1-4\left(\mathrm{mg} \mathrm{kg}^{-1}\right)$ & $\mathrm{P} 1-5\left(\mu \mathrm{gg}^{-1}\right)$ & P1-6 $\left(\mu \mathrm{g} \mathrm{kg}^{-1}\right)$ \\
\hline Distance (m) & 0 & 15 & 25 & 50 & 300 & 1000 \\
\hline TC & $1.12 \pm 0.11$ & $0.18 \pm 0.02$ & $0.06 \pm 0.01$ & $0.06 \pm 0.01$ & ND & ND \\
\hline ETC & $0.38 \pm 0.02$ & $0.08 \pm 0.01$ & ND & ND & ND & ND \\
\hline EATC & $0.82 \pm 0.06$ & $0.13 \pm 0.02$ & $0.09 \pm 0.01$ & ND & $0.86 \pm 0.05$ & $1.92 \pm 0.21$ \\
\hline OTC & $0.31 \pm 0.02$ & $0.75 \pm 0.08$ & $0.98 \pm 0.12$ & $0.06 \pm 0.12$ & $2.32 \pm 0.32$ & $4.23 \pm 0.38$ \\
\hline EOTC & $0.06 \pm 0.01$ & ND & $0.06 \pm 0.01$ & ND & ND & ND \\
\hline$\alpha$-OTC & $0.03 \pm 0.01$ & $0.28 \pm 0.02$ & ND & $0.03 \pm 0.01$ & ND & ND \\
\hline$\beta$-ОTC & ND & ND & $0.06 \pm 0.01$ & $0.04 \pm 0.01$ & $1.39 \pm 0.19$ & $5.36 \pm 0.64$ \\
\hline MTC & ND & ND & ND & ND & ND & ND \\
\hline DXC & ND & $0.03 \pm 0.01$ & $0.01 \pm 0.01$ & $0.01 \pm 0.01$ & ND & ND \\
\hline CTC & $25.79 \pm 2.18$ & $2.86 \pm 0.18$ & $1.08 \pm 0.13$ & $0.82 \pm 0.06$ & $3.12 \pm 0.23$ & $8.28 \pm 0.78$ \\
\hline ICTC & $9.11 \pm 1.21$ & $3.20 \pm 0.42$ & $1.02 \pm 0.21$ & $0.08 \pm 0.13$ & $1.22 \pm 0.13$ & $2.18 \pm 0.32$ \\
\hline
\end{tabular}

ND: not detected.

their degradation products as well as DTX and CTC in the sediment or soil are given in Table 5, respectively. The concentrations of TCs ranged from 0.78 to $277.00 \mu \mathrm{g} \mathrm{kg}^{-1}$, which were about 2-3 orders of magnitude lower than those found in Swine Farm 1. Neither the parent compound MTC nor the three degradation products of OTC were detected at P2-1. The concentrations of the detected antibiotics ranged from 1.09 to $37.55 \mu \mathrm{g} \mathrm{kg}^{-1}$. Among them, CTC reached $37.55 \mu \mathrm{g} \mathrm{kg}^{-1}$, which was the highest concentration found. The remaining antibiotics were all below $10.00 \mu \mathrm{g} \mathrm{kg}^{-1}$. The concentrations of all antibiotics were higher at P2-2 than at P2-1, which was $40 \mathrm{~m}$ away, and $\alpha$-OTC and $\beta$-OTC, the two degradation products of OTC, were also identified. Although concentrations at P2-2 were higher than those at P2-1, they were still several orders of magnitude lower than those at P1-1. Unlike P2-2, $\alpha$-OTC was not detected at P2-3, and the detected antibiotics ranged from 0.95 to $97.59 \mu \mathrm{g} \mathrm{kg}^{-1}$, which were $1-2$ orders of magnitude lower than those at P2-2.

For Swine Farm 3, the variations in concentrations of TC, OTC and their degradation products as well as DTX and CTC in sediment or soil are given in Table 6. With the exception of MTC, which was not found at any sampling point, all TCs were detected at least once. TC and its degradation product EATC, OTC and its degradation

Table 5

Concentrations of TCs $\left(\mu \mathrm{g} \mathrm{kg}{ }^{-1}\right)$ along the migration paths at Swine Farm 2.

\begin{tabular}{|c|c|c|c|c|c|}
\hline & P2-1 & P2-2 & P2-3 & P2-4 & P2-5 \\
\hline Distance (m) & 0 & 40 & 110 & 190 & 200 \\
\hline TC & $4.06 \pm 0.21$ & $18.02 \pm 2.32$ & $12.03 \pm 1.32$ & $3.06 \pm 0.34$ & $0.06 \pm 0.01$ \\
\hline ETC & $2.06 \pm 0.18$ & $12.03 \pm 3.21$ & $9.06 \pm 0.08$ & $3.26 \pm 0.21$ & ND \\
\hline EATC & $1.09 \pm 0.09$ & $3.02 \pm 0.18$ & $0.92 \pm 0.03$ & $0.32 \pm 0.04$ & ND \\
\hline OTC & $8.13 \pm 0.08$ & $7.05 \pm 0.86$ & $6.12 \pm 0.32$ & $3.12 \pm 0.21$ & $7.52 \pm 0.82$ \\
\hline EOTC & ND & ND & ND & ND & ND \\
\hline$\alpha$-OTC & ND & $9.02 \pm 0.12$ & ND & $3.84 \pm 0.31$ & $11.32 \pm 1.32$ \\
\hline$\beta$-OTC & ND & $1.82 \pm 0.14$ & $0.95 \pm 0.06$ & ND & ND \\
\hline MTC & ND & ND & ND & ND & ND \\
\hline DXC & $1.23 \pm 0.12$ & $2.35 \pm 0.32$ & $1.61 \pm 0.13$ & $0.78 \pm 0.06$ & $1.50 \pm 0.13$ \\
\hline CTC & $37.55 \pm 0.43$ & $282.12 \pm 30.24$ & $97.59 \pm 8.78$ & $40.86 \pm 3.82$ & $7.26 \pm 0.56$ \\
\hline ICTC & $8.08 \pm 0.12$ & $116.02 \pm 20.45$ & $11.06 \pm 1.43$ & $18.23 \pm 1.21$ & ND \\
\hline
\end{tabular}

ND: not detected. 
Table 6

Concentrations of TCs $\left(\mu \mathrm{gg}^{-1}\right)$ along the migration paths at Swine Farm 3.

\begin{tabular}{|c|c|c|c|c|c|c|c|c|}
\hline & P3-1 & P3-2 & P3-3 & P3-4 & P3-5 & P3-6 & P3-7 & P3-8 \\
\hline Distance (m) & 0 & 15 & 70 & 70 & 150 & 150 & 400 & 400 \\
\hline TC & $432.02 \pm 33.65$ & $4.32 \pm 3.56$ & $308.03 \pm 26.32$ & $5.12 \pm 0.36$ & $1.05 \pm 0.01$ & $0.43 \pm 0.08$ & $0.08 \pm 0.01$ & $0.48 \pm 0.03$ \\
\hline ETC & $182.36 \pm 16.32$ & $0.03 \pm 0.01$ & $196.32 \pm 20.36$ & $0.68 \pm 0.09$ & $11.20 \pm 0.56$ & $0.04 \pm 0.01$ & $0.06 \pm 0.01$ & $0.05 \pm 0.01$ \\
\hline EATC & $61.25 \pm 5.36$ & $2.03 \pm 0.23$ & $38.26 \pm 4.06$ & $2.23 \pm 0.18$ & $8.32 \pm 0.63$ & $0.86 \pm 0.03$ & $1.32 \pm 0.12$ & $0.76 \pm 0.06$ \\
\hline OTC & $1580.23 \pm 126.65$ & $88.56 \pm 13.36$ & $1163.25 \pm 200.30$ & $20.35 \pm 3.05$ & $16.32 \pm 1.32$ & $21.89 \pm 2.56$ & $11.08 \pm 2.08$ & $19.36 \pm 2.38$ \\
\hline EOTC & $600.12 \pm 56.32$ & $1.23 \pm 0.13$ & $400.35 \pm 46.23$ & $0.53 \pm 0.03$ & $11.03 \pm 2.02$ & $0.05 \pm 0.01$ & $6.03 \pm 0.74$ & $0.04 \pm 0.01$ \\
\hline$\alpha$-ОTC & $623.45 \pm 32.56$ & $22.32 \pm 2.98$ & $238.56 \pm 32.18$ & $17.68 \pm 1.25$ & $8.02 \pm 0.56$ & $6.34 \pm 0.12$ & $2.56 \pm 0.36$ & $1.42 \pm 0.22$ \\
\hline$\beta$-ОТС & $23.35 \pm 1.98$ & $1.13 \pm 0.23$ & $10.35 \pm 1.65$ & $0.42 \pm 0.02$ & $3.56 \pm 0.18$ & $0.06 \pm 0.01$ & $2.58 \pm 0.32$ & $0.03 \pm 0.01$ \\
\hline MTC & ND & ND & ND & ND & ND & ND & ND & ND \\
\hline DXC & $7000.32 \pm 500.36$ & $44.32 \pm 3.66$ & $4000.35 \pm 432.08$ & $32.02 \pm 4.02$ & $265.68 \pm 3.12$ & $5.31 \pm 0.45$ & $218.62 \pm 36.32$ & $1.02 \pm 0.16$ \\
\hline CTC & $58.32 \pm 6.89$ & $5.82 \pm 0.63$ & $11.69 \pm 2.06$ & $5.06 \pm 0.45$ & $0.58 \pm 0.06$ & $0.06 \pm 0.01$ & $6.43 \pm 0.84$ & $0.42 \pm 0.08$ \\
\hline ICTC & $40.16 \pm 4.65$ & ND & $8.23 \pm 0.83$ & ND & $2.12 \pm 0.18$ & ND & $0.98 \pm 0.05$ & ND \\
\hline
\end{tabular}

ND: not detected.

product $\alpha$-OTC, and the parent compound DXC were all detected. At the sewage outlet, the highest concentration found was DXC at $7.10 \mathrm{mg} \mathrm{kg}^{-1}$, followed by OTC at $1.53 \mathrm{mg} \mathrm{kg}^{-1}$, which was slightly lower than that in Swine Farm 1. Table 6 shows that the concentration of ETC at P3-3 was higher than that at P3-1, but all other TCs detected along the migration path were found at higher concentrations at P3-1.

The concentrations at P3-5 and P3-7 were roughly equal, and ranged from 1.31 to $190.49 \mu \mathrm{g} \mathrm{kg}^{-1}$ and from 0.77 to $249.24 \mu \mathrm{g} \mathrm{kg}^{-1}$, respectively. Despite the higher concentration of DXC, OTC at P3-5 and P3-7 varied from 0.04 to $0.25 \mathrm{mg} \mathrm{kg}^{-1}$, while the concentrations of other TCs were below $10.00 \mu \mathrm{g} \mathrm{kg}^{-1}$.

At Swine Farm 3, all antibiotics were detected in the sewageirrigated paddy soil, with the exception of MTC and ICTC. The concentrations of DXC and OTC reached 88.98 and $42.75 \mu \mathrm{g} \mathrm{kg}^{-1}$, respectively. After the $385 \mathrm{~m}$ migration distance through paddy soil, concentrations of most TCs at P3-8 were lower than $10.00 \mu \mathrm{g} \mathrm{kg}^{-1}$. However, the $\Sigma \mathrm{TCs}$ concentrations at the four points (P3-2, P3-4, P3-6, P3-8) along the path were 168.34, 83.99, 32.57 and $23.62 \mu \mathrm{g} \mathrm{kg}^{-1}$, respectively. Notably, at P3-2 the $\Sigma$ TCs concentration was more than $100.00 \mu \mathrm{g} \mathrm{kg}^{-1}$, which is the threshold for triggering eco-toxicological effects. In contrast, all antibiotics were detected with the exception of MTC in the sewer sediment. Furthermore, the concentrations of TCs along the $385 \mathrm{~m}$ sewer sediment path differed from those along the paddy soil path of the same length. The $\Sigma$ TCs concentrations at P3-3, P3-5 and P3-7 points along the path were $66367.16,327.88$ and $249.74 \mu \mathrm{g} \mathrm{kg}^{-1}$, respectively, which were $1-3$ orders of magnitude higher than those at P3-4, P3-6 and P3-8.
For Swine Farm 4, the variations in concentrations of TC, OTC and their degradation products, as well as DTX and CTC in the sediment or soil, are given in Table 7. Only four antibiotics, that is, OTC, $\alpha$-OTC, DXC and CTC, were detected at the P4- 1 sewage outlet. The concentrations of the above compounds ranged from 1.02 to $21.52 \mu \mathrm{g} \mathrm{kg}^{-1}$, and were the lowest of the values from all four farms. Among them, OTC had the highest concentration. Similar to Swine Farm 2, the concentrations of TCs in the sewer sediments (P4-3) ranged from 2.17 to $659.07 \mu \mathrm{g} \mathrm{kg}^{-1}$, which were higher than those at P4-1. The concentrations of TCs at P4-5, which contained mixedcanal sediment, decreased rapidly except for EATC; however, they were higher than those found at P4-1. When the mixed-canal sediments from Swine Farm 4 and 2 were compared, Swine Farm 4 had lower concentrations of TC and its degradation products, while OTC and its degradation products were higher than those found in Swine Farm 2. The concentration of OTC and DXC at P4-5 was $95.31 \mu \mathrm{g} \mathrm{kg}^{-1}$, which was almost reaching the $100.00 \mu \mathrm{g} \mathrm{kg}^{-1}$ threshold.

Antibiotics were detected at P4-2 and P4-4 with concentrations ranging from 0 to $22.34 \mu \mathrm{g} \mathrm{kg}^{-1}$. The concentration of $\alpha$-OTC was lower in farmland soil samples than that in mixed-canal sediments at Swine Farm 4. The concentrations of TC, OTC, $\alpha$-OTC and DXC in upland soil samples were lower than those in paddy field soil, whereas the concentrations of EATC and CTC showed the opposite trend. The concentrations of TCs in the upland soil ranged from 0 to $17.94 \mu \mathrm{g} \mathrm{kg}^{-1}$ and the $\Sigma \mathrm{TCs}$ concentration was $29.92 \mu \mathrm{g} \mathrm{kg}^{-1}$. In paddy soil, the concentration of TCs ranged from 0 to $22.34 \mu \mathrm{g} \mathrm{kg}^{-1}$, and the $\Sigma$ TCs concentration was $54.00 \mu \mathrm{g} \mathrm{kg}^{-1}$. Interestingly, although the upland field was closer to the farm outlet point than

Table 7

Concentrations of TCs $\left(\mu \mathrm{gg}^{-1}\right)$ along the migration paths at Swine Farm 4.

\begin{tabular}{|c|c|c|c|c|c|}
\hline & P4-1 & P4-2 & P4-3 & P4-4 & P4-5 \\
\hline Distance (m) & 0 & 30 & 100 & 100 & 150 \\
\hline TC & ND & ND & $2.17 \pm 0.18$ & $3.08 \pm 0.21$ & ND \\
\hline ETC & ND & ND & ND & ND & ND \\
\hline EATC & ND & $1.92 \pm 0.24$ & ND & $1.58 \pm 0.08$ & $0.62 \pm 0.10$ \\
\hline OTC & $1.02 \pm 0.12$ & ND & $659.07 \pm 38.34$ & ND & $89.23 \pm 5.02$ \\
\hline EOTC & ND & ND & $180.20 \pm 15.30$ & ND & $2.03 \pm 0.35$ \\
\hline$\alpha$-ОТС & $21.52 \pm 2.38$ & $18.34 \pm 2.53$ & $61.08 \pm 3.56$ & $23.8 \pm 1.97$ & $1.02 \pm 0.16$ \\
\hline$\beta$-OTC & ND & ND & ND & ND & $0.22 \pm 0.08$ \\
\hline MTC & ND & ND & ND & ND & ND \\
\hline DXC & $2.38 \pm 0.52$ & $1.83 \pm 0.18$ & $11.53 \pm 0.86$ & $16.48 \pm 2.32$ & $6.08 \pm 0.35$ \\
\hline CTC & $1.12 \pm 0.12$ & $3.82 \pm 0.36$ & $2.84 \pm 0.17$ & ND & ND \\
\hline ICTC & ND & ND & ND & ND & ND \\
\hline
\end{tabular}

ND: not detected. 
Table 8

Types and coefficients for variations in concentrations of target antibiotics with distance along each migration path.

\begin{tabular}{|c|c|c|c|c|c|c|c|c|c|c|c|c|c|}
\hline & & \multicolumn{3}{|c|}{ Swine Farm 1} & \multicolumn{3}{|c|}{ Swine Farm 2} & \multicolumn{3}{|c|}{ Swine Farm 3(p) } & \multicolumn{3}{|c|}{ Swine Farm 3(s) } \\
\hline & & Type & Coefficient & $\begin{array}{l}\text { Half-life } \\
\text { distance }(\mathrm{m})\end{array}$ & Type & Coefficient & $\begin{array}{l}\text { Half-life } \\
\text { distance }(\mathrm{m})\end{array}$ & Type & Coefficient & $\begin{array}{l}\text { Half-life } \\
\text { distance (m) }\end{array}$ & Type & Coefficient & $\begin{array}{l}\text { Half-life } \\
\text { distance }(\mathrm{m})\end{array}$ \\
\hline \multirow{3}{*}{$\begin{array}{l}\text { TC and degradation } \\
\text { products }\end{array}$} & $\mathrm{TC}$ & $E$ & -4.64 & 10 & $\mathrm{~L}$ & -8.25 & 120 & $E$ & -1.75 & 2 & $\mathrm{~L}$ & -2.40 & 145 \\
\hline & ETC & $\mathrm{E}$ & -4.92 & 8 & $\mathrm{~L}$ & -4.95 & 135 & $\mathrm{E}$ & -1.52 & 2 & $\mathrm{~L}$ & -0.29 & 155 \\
\hline & EATC & $\mathrm{E}$ & -4.26 & 8 & $\mathrm{E}$ & -1.09 & 41 & $\mathrm{~L}$ & -22.44 & 3 & $\mathrm{E}$ & -0.62 & 150 \\
\hline \multirow{4}{*}{$\begin{array}{l}\text { OTC and degradation } \\
\text { products }\end{array}$} & OTC & $E$ & -1.99 & 23 & $\mathrm{~L}$ & -1.87 & 180 & $\mathrm{~L}$ & -554.80 & 2 & $E$ & -0.53 & 70 \\
\hline & EOTC & $\mathrm{L}$ & -15.46 & 24 & $\mathrm{~N}$ & & & $\mathrm{~L}$ & -212.06 & 2 & $\mathrm{~N}$ & & \\
\hline & $\alpha$-OTC & $\mathrm{L}$ & -132.53 & 25 & $\mathrm{~L}$ & -3.14 & 100 & $\mathrm{E}$ & -1.91 & 3 & $\mathrm{~L}$ & -7.02 & 150 \\
\hline & $\beta$-OTC & $\mathrm{N}$ & & & $\mathrm{L}$ & -0.64 & 120 & $\mathrm{E}$ & -1.06 & 1 & $\mathrm{~L}$ & -0.36 & 110 \\
\hline \multirow{4}{*}{$\begin{array}{l}\text { CTC and degradation } \\
\text { products }\end{array}$} & СТC & $\mathrm{E}$ & -2.90 & 22 & $\mathrm{E}$ & -0.96 & 80 & $\mathrm{~L}$ & -17.28 & 2 & $\mathrm{~L}$ & -1.53 & 130 \\
\hline & ICTC & $\mathrm{E}$ & -1.99 & 6 & $\mathrm{~L}$ & -49.81 & 100 & $\mathrm{~L}$ & -19.94 & 2 & $\mathrm{~N}$ & & \\
\hline & DXC & $\mathrm{E}$ & -1.24 & 7 & $\mathrm{~L}$ & -0.79 & 150 & $\mathrm{~L}$ & -2428.20 & 2 & $\mathrm{E}$ & -1.19 & 68 \\
\hline & $\Sigma \mathrm{TCS}$ & $E$ & -2.20 & 8 & $E$ & -0.97 & 90 & $\mathrm{~L}$ & -3713.30 & 2 & $\mathrm{E}$ & -0.68 & 70 \\
\hline
\end{tabular}

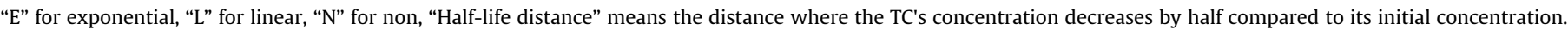

the paddy field, antibiotic concentrations and $\Sigma$ TCs were both higher in paddy soil.

\subsection{Decay of TCs along different migration paths of the four farms}

It was found that the concentration of TCs demonstrated an obvious attenuation/decay along the migration paths (Table 8 and Appendix 1). As the total sample length of Swine Farm 1 was quite long, the first $50 \mathrm{~m}$ was chosen to obtain intensive sampling points. We investigated how concentrations of TCs in sediment (or soil) changed with distance along the first $50 \mathrm{~m}$ of the migration paths. As shown in Table 4 and Table 8, concentrations of TC, ETC, EATC, ICTC, OTC, CTC, DXC and $\Sigma$ TCs decreased exponentially with distance, following the equation $y=A^{*} \exp (B x)$; however, the concentration of EOTC decreased linearly following the equation $y=M x+K$, where $B$ and $M$ are the attenuation coefficients, as listed in Table 8; $x$ is distance from the source; $y$ is the TC concentration which corresponds to the distance $x ; A$ and $K$ are constants based on the specific attenuation equation. In comparison, the concentrations of OTC, $\alpha$-OTC and DXC increased significantly in the sewage pond. $\beta$-OTC, a degradation product of OTC, was only detected at P1-3 and P1-4, so it was not possible to establish a degradation relation.

Both OTC and DXC demonstrated an exponential decrease along the $30 \mathrm{~m}$ migration path from P1-2 to P1-4, while $\alpha$-OTC exhibited a linear decrease. The attenuation coefficient values showed that ETC degradation was the fastest, followed by TC, with OTC being the slowest. The OTC degradation products EOTC and $\alpha$-OTC displayed linear attenuation at a rate significantly lower than that of the other TCs.

The antibiotics detected at P2-4 were almost the same as those at P2-3. Concentrations at P2-4 continued to decline from the range of $0.95-97.59 \mu \mathrm{g} \mathrm{kg}^{-1}$ to the range of $0.78-40.86 \mu \mathrm{g} \mathrm{kg}^{-1}$, but the rate of attenuation was low. Unlike the exponential decrease characteristics observed in Swine Farm 1, the majority of the attenuation functions in Swine Farm 2 were linear. The attenuation rate of OTC was slower than that of TC. The attenuation coefficients of the above compounds are shown in Table 8, and were consistent with the results of Swine Farm 1. EATC, CTC and $\Sigma$ TCs decreased exponentially in Swine Farm 2, but the absolute values of the attenuation coefficients were much lower than those in Swine Farm 1.

As distance from the point source increased, the attenuation rates of most TCs in the mixed-canal became slower for all four farms (Table 8). For P2-5 paddy soil, the $\Sigma$ TCs concentration was $26.05 \mu \mathrm{g} \mathrm{kg}^{-1}$, which was lower than that of P1-4, but higher than that of P1-5. Furthermore, the concentrations of TC, its degradation products and CTC were lower than those at P2-4; while those of OTC, its degradation products and DXC were higher.

With the increase in distance along the migration path, the concentration of TC and its degradation product ETC, and OTC and its degradation products $\alpha$-OTC and $\beta$-OTC, decreased exponentially at different rates (Table 8), while the concentrations of the other TCs decreased linearly. It is clear from the attenuation coefficients that the attenuation rate in the sewer was higher than that in the mixed-canal in Swine Farm 2. The concentration ranges of TCs at both P3-5 and P3-7 were similar, and ranged from 1.31 to $190.49 \mu \mathrm{g} \mathrm{kg}^{-1}$ and from 0.77 to $249.24 \mu \mathrm{g} \mathrm{kg}^{-1}$, respectively. The concentration ranges of TCs at both P3-5 and P3-7 were also similar to those in P2-2, but the concentrations of TCs at P3-1 were much higher than those at P2-1. Despite higher concentrations of DXC and OTC at both P3-5 and P3-7, which ranged from 0.04 to $0.25 \mathrm{mg} \mathrm{kg}^{-1}$, the concentrations of the other TCs were below $10.00 \mu \mathrm{g} \mathrm{kg}^{-1}$.

Among the antibiotics at Swine Farm 2 and 3(p), both TC and ETC showed a linear decrease. In Swine Farm 1 and 3(s), ETC displayed an exponential decrease, making the attenuation of TCs (TC, ETC, EATC and ICTC) opposite to that observed in the sewer. The attenuation functions of OTC and its degradation products were completely different from those of TC, ETC, EATC and ICTC. The concentration of OTC decreased along the entire path (EOTC was only detected at P3-4) in an exponential fashion. In contrast, $\alpha$-OTC and $\beta$-OTC showed linear decreases in their concentrations. However, similar to the TC class, the OTC class (OTC, EOTC, $\alpha$-OTC and $\beta$-OTC) in the paddy soil showed the opposite trend to that observed in the sewer sediment. Furthermore, DXC attenuation was similar to that of OTC, while CTC was similar to that of TC, and the $\Sigma$ TCs concentration displayed exponential attenuation.

\subsection{Relationship of the TC distribution characteristics between the basin and the river}

As can be seen from Table 9, the detection rates and the detected concentrations of all the TCs except CTC were consistent between the wastewater samples of the farm outlets and the sediment samples. In contrast, the CTC detection rate was $25.0 \%$ in the wastewater while the detection rate was $100.0 \%$ in sediment samples. This may be because CTC was rapidly transformed into isochlortetracycline and epi-isochlortetracycline in wastewater by ring-opening reactions, but was more associated with the 
Table 9

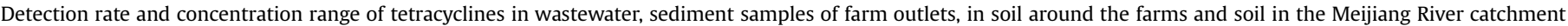
samples.

\begin{tabular}{|c|c|c|c|c|c|c|c|c|c|}
\hline \multirow[t]{2}{*}{ TCs } & & \multicolumn{2}{|c|}{$\begin{array}{l}\text { Wastewater samples } \\
\text { of farm outlets }\end{array}$} & \multicolumn{2}{|c|}{$\begin{array}{l}\text { Sediment samples } \\
\text { of farm outlets }\end{array}$} & \multicolumn{2}{|c|}{$\begin{array}{l}\text { Soil samples from } \\
\text { around the farms }\end{array}$} & \multicolumn{2}{|c|}{$\begin{array}{l}\text { Soil in the Meijiang } \\
\text { River Catchment samples }\end{array}$} \\
\hline & & $\begin{array}{l}\text { Detection } \\
\text { rate/\% }\end{array}$ & $\begin{array}{l}\text { Concentration/ } \\
\left(\mu \mathrm{g} \mathrm{L}^{-1}\right)\end{array}$ & $\begin{array}{l}\text { Detection } \\
\text { rate/\% }\end{array}$ & $\begin{array}{l}\text { Concentration/ } \\
\left(\mathrm{mg} \mathrm{kg}^{-1}\right)\end{array}$ & $\begin{array}{l}\text { Detection } \\
\text { rate/\% }\end{array}$ & $\begin{array}{l}\text { Concentration/ } \\
\left(\mu \mathrm{g} \mathrm{kg}^{-1}\right)\end{array}$ & $\begin{array}{l}\text { Detection } \\
\text { rate/\% }\end{array}$ & $\begin{array}{l}\text { Concentration/ } \\
\left(\mu \mathrm{g} \mathrm{kg}^{-1}\right)\end{array}$ \\
\hline \multirow[t]{3}{*}{ TC } & TC & 75.00 & $0.74 \pm 0.03$ & 75.00 & $0.39 \pm 0.02$ & 44.44 & $1.03 \pm 0.13$ & 25.93 & $0.69 \pm 0.04$ \\
\hline & ETC & 100.00 & $0.64 \pm 0.02$ & 75.00 & $0.12 \pm 0.01$ & 11.11 & $0.06 \pm 0.01$ & 7.41 & $0.21 \pm 0.02$ \\
\hline & EATC & 50.00 & $0.17 \pm 0.01$ & 75.00 & $0.15 \pm 0.01$ & 77.78 & $1.30 \pm 0.12$ & 77.78 & $3.45 \pm 0.42$ \\
\hline \multirow[t]{4}{*}{ OTC } & OTC & 100.00 & $35.23 \pm 4.32$ & 100.00 & $0.47 \pm 0.03$ & 100.00 & $16.54 \pm 2.22$ & 100 & $21.59 \pm 3.21$ \\
\hline & EOTC & 50.00 & $4.31 \pm 0.21$ & 50.00 & $0.16 \pm 0.02$ & 11.11 & $0.06 \pm 0.01$ & ND & ND \\
\hline & $\alpha$-OTC & 25.00 & $1.20 \pm 0.11$ & 75.00 & $0.18 \pm 0.02$ & 77.78 & $6.88 \pm 0.34$ & 51.85 & $9.38 \pm 0.64$ \\
\hline & $\beta$-OTC & ND & ND & 25.00 & $0.01 \pm 0.01$ & 33.33 & $0.27 \pm 0.03$ & 51.85 & $1.18 \pm 0.14$ \\
\hline \multicolumn{2}{|c|}{ MTC } & ND & ND & ND & ND & ND & ND & ND & ND \\
\hline \multicolumn{2}{|c|}{ СТС СТС } & 25.00 & $3.82 \pm 0.24$ & 100.00 & $6.47 \pm 0.43$ & 66.67 & $3.36 \pm 0.43$ & 25.93 & $2.83 \pm 0.32$ \\
\hline \multicolumn{2}{|c|}{ ICTC } & 100.00 & $9.32 \pm 0.34$ & 75.00 & $2.23 \pm 0.18$ & 22.22 & $6.85 \pm 0.82$ & 11.11 & $0.84 \pm 0.06$ \\
\hline \multicolumn{2}{|c|}{ DXC } & 75.00 & $1.95 \pm 0.21$ & 75.00 & $1.78 \pm 0.12$ & 100.00 & $7.49 \pm 0.86$ & 77.78 & $1.86 \pm 0.12$ \\
\hline
\end{tabular}

ND: not detected.

sediment, because sediment had dissolved organic carbon (DOC) and colloidal matter to adsorb TCs and potentially keep them in suspension. The detection rates of all the TCs (except OTC and MTC) showed no consistent pattern in the wastewater of the outlet of the farms, the sediment and the paddy soil. OTC detection rates were $100.0 \%$, and MTC was not detected in the three media (water, sediment and paddy soil). The detection rates of the rest of the TCs, such as TC and its degradation products ETC and ICTC in wastewater of the outlets and sediment samples, were higher than those in soil. This indicated that these TCs were more likely to be adsorbed or undergo degradation compared with OTC. EOTC, which is the degradation product of OTC, was not detected in all soil samples, while it was detected in the wastewater of the farm outlets, indicating that EOTC was not the main degradation product in the process of migration and was easy to degrade. The detection rates of $\alpha$-OTC in the wastewater of the farm outlets, in the sediments, and in the soil were $25.00 \%, 75.00 \%$ and $51.85 \%$, respectively, implying that it was more easily adsorbed in the sediment and soil than in the water.

\section{Discussion}

The $\mathrm{mg} \cdot \mathrm{L}^{-1}$ and $\mathrm{mg} \cdot \mathrm{kg}^{-1}$ detection levels of TCs in the farm outlet samples, which were similar to those reported in livestock manure samples (Christian et al., 2003; Martinez-Carballo et al., 2007; Zhao et al., 2010), indicates that they are an integral component of swine management at these and most likely almost all swine farms. However, antibiotic concentrations are completely influenced by their forms and by environmental factors such as DOC, organic matter, co-existing cations, iron oxides in soil and sediment, $\mathrm{pH}$, temperature, and illumination intensity (Hu et al., 2010).

\subsection{Influence of TC forms on degradation}

In this study, varied features were observed among TCs, particularly between TC and OTC. First, the concentration of TC at the sewage pond (P1-2) was lower than that found at P1-1, while the opposite pattern was observed for OTC at Swine Farm 1. Second, the attenuation rate of OTC was slower than that of TC in the mixedcanal, paddy soil and sewer samples except for paddy soil at $385 \mathrm{~m}$ in Swine Farm 3. Furthermore, the concentrations of TC and its degradation products at P2-5 were lower than those at P2-4, while
OTC and its degradation products were higher. Finally, concentrations of the TC class increased initially and then decreased with distance, while the concentrations of the OTC class decreased along the entire path. Differences in sorption characteristics and persistence might be responsible for these discrepancies in the presence of the above compounds under different environmental conditions.

The less steep decrease in concentration of OTC in the sewer and paddy soil indicated that it is not as rapidly degraded as TC and CTC. In addition, the adsorption of TC in soil is reportedly stronger than that of OTC, with sorption coefficients $\left(\mathrm{K}_{\mathrm{d}}\right)$ of TC and OTC ranging from 1147 to $23701 \mathrm{~kg}^{-1}$ and $417-1026 \mathrm{l} \mathrm{kg}^{-1}$ (Sarmah et al., 2006), respectively, implying that the TC concentration is more easily attenuated due to sorption than OTC. Thus, compared with TC and CTC, OTC was more stable and more easily transported. Similar conclusions could also be drawn for $\alpha$-OTC, a degradation product of OTC, and for DXC (Table 4). These results suggest that the TC class tended to deposit in relatively stable water-sediment environments (ponds), while OTC migrated more readily.

\subsection{Influence of migration path on TC degradation}

This study showed that the concentrations of TCs mostly decreased with migration distance. There may be several reasons for this behavior. First, TCs were bound strongly to the soil or sediment (Sarmah et al., 2006); therefore, less horizontal movement occurred. Second, some TC degradation occurred during migration. Furthermore, due to dilution by the import of water from a nearby stream, the TC concentrations at P2-3 and P4-5 were much lower than those at P2-2 and P4-3, respectively. At P4-2, although there was no direct in-flow of sewage, several kinds of TCs were detected. This was possibly due to overland flow, which has been identified as a route by which veterinary antibiotics can be transported to surface waters, or at least closer to them (Kay et al., 2005).

The attenuation in the sewer was more pronounced than that in the mixed-canal, which may be due to relatively higher flow speed in the mixed canal compared with that in the sewer. Comparing sewer sediments and paddy soil samples along the same migration distance, such as P3-3 and P3-4, P3-5 and P3-6, and P3-7 and P3-8, it was found that all TCs were 1-3 orders of magnitude higher in the sewers than in the corresponding paddy fields (with the exception of MTC and ICTC, which were not detected). This is 
because TCs are bound to sediment particles, and high flow speed could cause particles to suspend in water, which could, in turn, allow for further transportation downstream. Rico et al. (2014) also reported that an increase in flow velocity likely contributed to higher antibiotic desorption and re-suspension from sediments. The decay rates of TCs in the sewer and paddy soil for the same migration length were completely different. In general, TCs decayed with distance exponentially in paddy soil, while linearly in the mixed canal and sewer. However, the concentration differences between sewer sediments and paddy soil finally became very small as migration distance increased, suggesting that the attenuation rate of TCs in the sewer was much faster than those in the paddy soil (Table 8). In contrast to paddy field soil, the concentration of TCs in the upland soil was lower, despite its being closer to the outlet. Also, the concentrations of TC degradation products were sharply lower at P1-3 than those at P1-2. Both could be attributed to the higher adsorption and then more rapid degradation of TCs in the relatively dry soil environment (Bao, 2008), whereas in the water-sediment system, TCs tended to be more stable and more easily accumulated.

In Swine Farms 2 and 4, the concentrations of TC at P2-2 and P4-3 were higher than those of their respective outlet samples. This was likely due to the outlet samples being exposed to sunlight, where photolysis occurred, while P2-2, P4-3 and the entire $40 \mathrm{~m}$ - and $100 \mathrm{~m}$-long sewers were under the shade of plants, thus experiencing less photolysis. Kuang et al. (2007) found that the extent of CTC reduction under dark conditions dropped below $10 \%$ within 15 days with different concentrations of manure, while degradation reached $90 \%$ under natural light conditions. Combining the previous findings and this study, photolysis may be a possibility for the decreased concentrations; however, photolysis experiments would need to be conducted to investigate to what extent it may occur at these farms. Our results may also be attributed to significant differences between soil degradation of organic pollutants by different plants (Cai et al., 2008), which is further related to physiological and biochemical characteristics of plant root exudates, as well as structural and functional differences in the rhizosphere microbial community (Li et al., 2011).

The study clearly revealed that TCs tended to be more stable and more easily accumulated in water-sediment system such as sewer ponds, hence aqueous or sediment erosion control could reduce the transport of veterinary antibiotics and prevent it from polluting the receiving rivers.

\subsection{Limitations of this study and future work}

The migration of antibiotics from manure to soil or watersediment is a complex process. Although research has been conducted on antibiotic degradation processes in laboratory set-ups, simulation experiments are often quite different from what is observed under real field scenarios. The current work did not consider the intermediate processes involved during antibiotic migration, such as plant uptake and runoff. In this study, the attenuation functions of TCs along different paths were obtained by data fitting, and the mechanism for the migration and transformation of TCs was analyzed based on previous research and the surrounding environment. Thus, additional data are still needed to validate the analyses.

This study showed the dominant presence of TCs in the Meijiang River basin, which were discharged into its tributaries from surrounding swine farms. This underscores the need to consider more efficient practices for management of livestock waste and aquaculture drainage, and their treatment prior to reuse or discharge. Given the persistence and high migration propensity of TCs, further research is necessary to better understand their fate in the environment, their impact on the establishment and amplification of antibiotic-resistant micro-organisms, and the associated risks to public health.

\section{Acknowledgments}

This work was supported by the National Nature Science Foundation of China $(51425902,91547206)$ and the Jiangsu Water Department (2015005). We are grateful to the editor and the two anonymous reviewers for their valuable comments and suggestions. Special thanks also go to Dr. Catharine Rice from USA and Dr. Christine Watts from Australia for proofreading the English.

\section{Appendix 1}

Optimal fitting formulas of the target antibiotics with distance along each migration path.

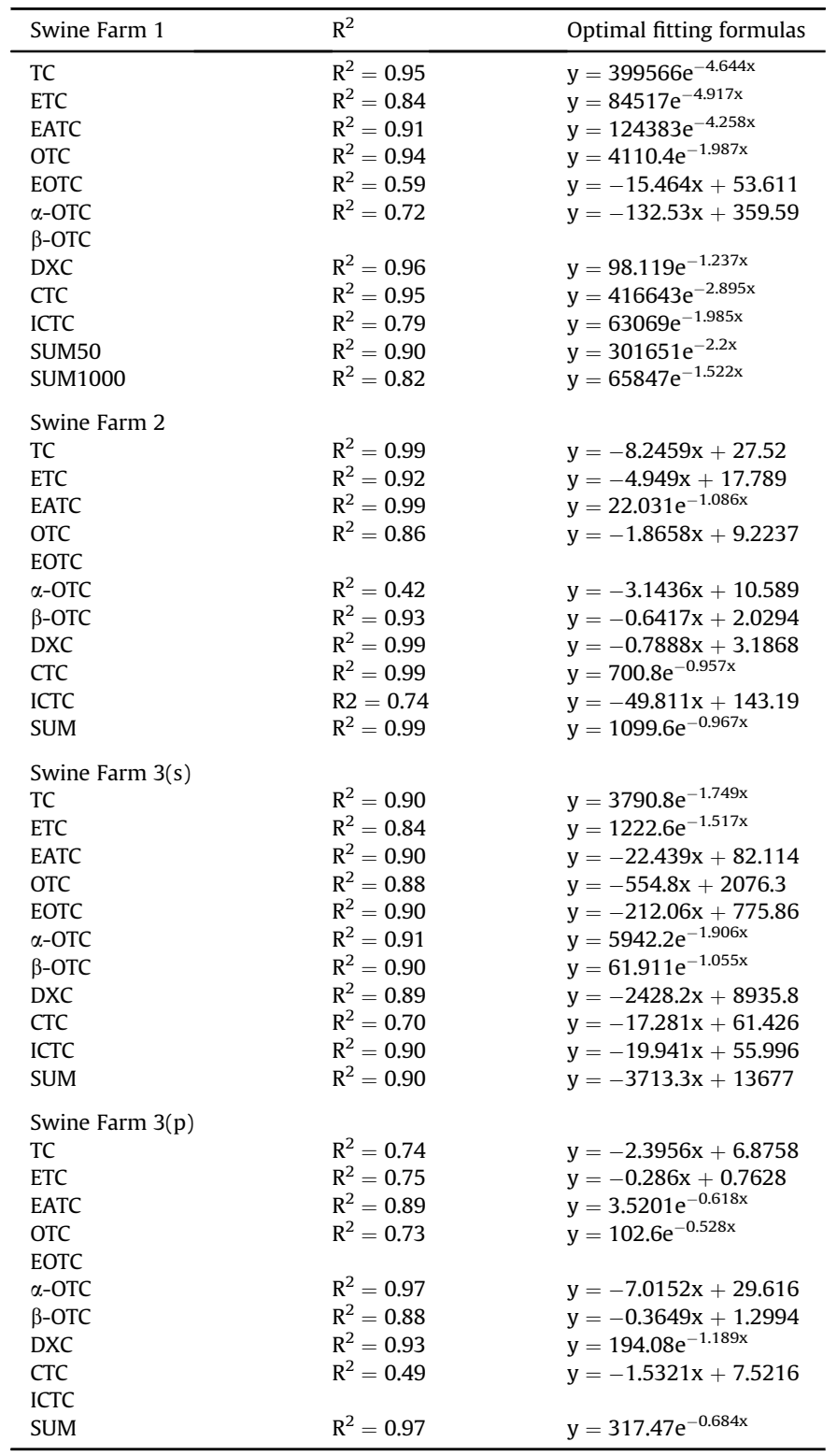



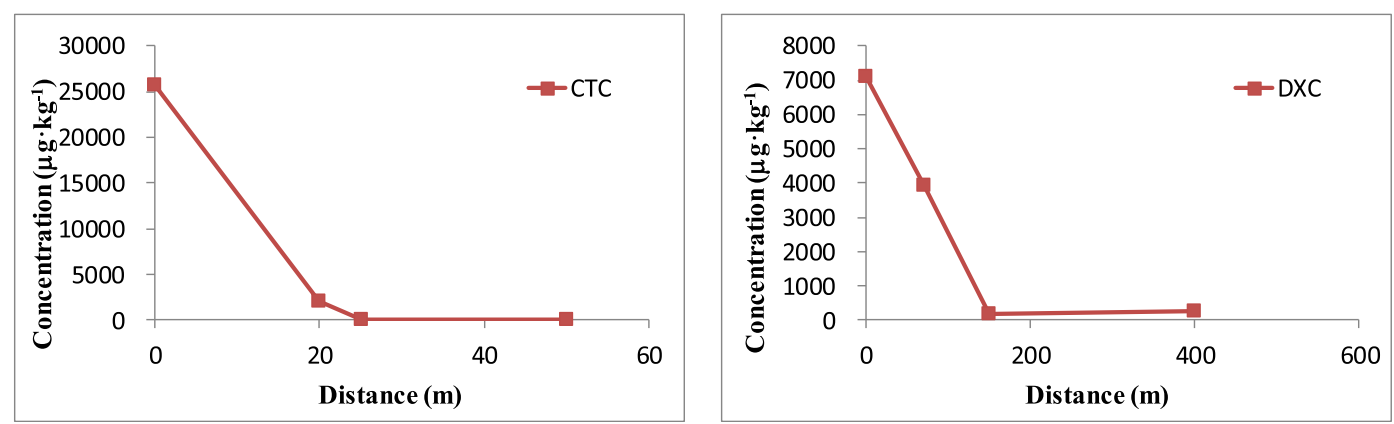

Fig. 1A. DXC Concentration in the sediment of paddy soil and CTC concentration in the sediment of sewer along distance.

\section{References}

Aust, M.O., Frauke, G., Greg, R.T., Hao, X.Y., McAllister, T.A., Leinweber, P., ThieleBruhn, S., 2008. Distribution of sulfamethazine, chlortetracycline and tylosin in manure. Environ. Pollut. 163, 1243-1251. http://dx.doi.org/10.1016/ j.envpol.2008.03.011.

Bao, Y., 2008. Environmental Behavior and Eco-toxicity of Tetracycline Antibiotics in Soils. Nankai University, pp. 56-62 [in Chinese with English abstract].

Cai, Q., Mo, C., Zeng, Q., Wu, Q., Férard, J.F., Ladislao, B.A., 2008. Potential of Ipomoea aquatica cultivars in phytoremediation of soils contaminated with di-n-butyl phthalate. Environ. Exp. Bot. 62 (3), 205-211. http://dx.doi.org/10.1016/ j.envexpbot.2007.08.005.

Chen, Y., Zhang, H., Luo, Y., 2010. A preliminary study on the occurrence and dissipation of antibiotics in swine wastewater. Acta Sci. Circumstantiae 30 (11), 2205-2212 [in Chinese with English abstract].

Christian, T., Schneider, R.J., Färber, H.A., Skutlarek, D., Meyer, M.T., Goldbach, H.E., 2003. Determination of antibiotic residues in manure, soil, and surface waters. Acta Hydroch Hydrob 31 (1), 36-44. http://dx.doi.org/10.1002/ aheh.200390014.

Hamscher, G., Sczesny, S., Abu-Qare, A., Höper, H., Nau, H., 2000. Substances with pharmacological effects including hormonally active substances in the environment: identification of tetracyclines in soil fertilized with animal slurry. Deutsche Tierarztliche Wochenschrift 107 (8), 332-334 [in German with English abstract].

Hamscher, G., Sczesny, S., Höper, H., Nau, H., 2002. Determination of persistent tetracycline residues in soil fertilized with liquid manure by high-performance liquid chromatography with electrospray ionization tandem mass spectrometry. Anal. Chem. 74 (7), 1509-1518. http://dx.doi.org/10.1021/ac015588m.

He, D., Xu, Z., Wen, G., 2011. Progress on residues and environmental behavior of tetracycline antibiotics. Prog.Veteri. Med. 32 (4), 98-102 [in Chinese with English abstract].

Hu, X., Zhou, Q., Luo, Y., 2010. Occurrence and source analysis of typical veterinary antibiotics in manure, soil, vegetables and groundwater from organic vegetable bases, northern China. Environ. Pollut. 158 (9), 2992-2998. http://dx.doi.org/ 10.1016/j.envpol.2010.05.023.

Jacobsen, A.M., Halling-Sorensen, B., 2006. Multi-component analysis of tetracyclines, sulfonamides and tylosin in swine manure by liquid chromatographytandem mass spectrometry. Anal. Bioanal. Chem. 384 (5), 1164-1174. http:// dx.doi.org/10.1007/s00216-005-0261-9.

Kay, P., Blackwell, P.A., Boxall, A.B.A., 2005. Transport of veterinary antibiotics in overland flow following the application of slurry to arable land. Chemosphere 59 (7), 951-959. http://dx.doi.org/10.1016/j.chemosphere.2004.11.055.

Karci, A., Balcioglu, I.A., 2009. Investigation of the tetracycline, sulfonamide, and fluoroquinolone antimicrobial compounds in animal manure and agricultural soils in Turkey. Sci. Total Environ. 407 (16), 4652-4664. http://dx.doi.org/ 10.1016/j.scitotenv.2009.04.047.

Kim, S.C., Davis, J.G., Truman, C.C., Ascough II, J.C., Carlson, K., 2010. Simulated rainfall study for transport of veterinary antibiotics-mass balance. J. Hazard. Mater 175, 836-843. http://dx.doi.org/10.1016/j.jhazmat.2009.10.086.

Kuang, G., Deng, F., Dong, Y., 2007. Study on the degradation of antibacterial medicine of tetracyclines in chicken Feces. Prog. Veteri. Med. 28 (6), 50-52 [in Chinese with English abstract].

Li, Y., Wu, X., Mo, C., Tai, Y., Huang, X., Xiang, L., 2011. Investigation of sulfonamide, tetracycline, and quinolone antibiotics in vegetable farmland soil in the Pearl River Delta area, southern China. J. Agric. Food. Chem. 59 (13), 7268-7276. http://dx.doi.org/10.1021/jf1047578.

Liu, X., Dong, Y., Wang, H., 2008. Residues of tetracyclines in animal manure from intensive farm in Jiangsu Province. J. Agro-Environ. Sci. 27 (3), 1177-1182 [in
Chinese with English abstract].

Luo, Y., Xu, L., Rysz, M., Wang, Y., Zhang, H., Alvarez, Р.J., 2011. Occurrence and transport of tetracycline, sulfonamide, quinolone, and macrolide antibiotics in the Haihe River Basin, China. Environ. Sci. Technol. 45, 1827-1833. http:// dx.doi.org/10.1021/es104009s.

Martinez-Carballo, E., González-Barreiro, C., Scharf, S., Gans, O., 2007. Environmental monitoring study of selected veterinary antibiotics in animal manure and soils in Austria. Environ. Pollut. 148 (2), 570-579. http://dx.doi.org/10.1016/ j.envpol.2006.11.035.

McArdell, C.S., Molnar, E., Suter, M.J.F., Giger, W., 2003. Occurrence and fate of macrolide antibiotics in wastewater treatment plants and in the Glatt Valley Watershed. Switz. Environ. Sci. Technol. 37, 5479-5486. http://dx.doi.org/ 10.1021/es034368i.

National Bureau of Statistics, 2014. China Statistical Year Book 2008. China Statistics Press, Beijing, pp. 136-140 [in Chinese].

Qiao, M., Chen, W., Su, J., Zhang, B., 2012. Fate of tetracyclines in swine manure of three selected swine farms in China. J. Environ. Sci. 24 (6), 1047-1052. http:// dx.doi.org/10.1016/S1001-0742(11)60890-5.

Rico, A., Oliveira, R., McDonough, S., Master, A., Khatikarn, J., Satapornvait, K., et al. 2014. Use, fate and ecological risks of antibiotics applied in tilapia cage farming in Thailand. Environ. Pollut. 191, 8-16. http://dx.doi.org/10.1016/ j.envpol.2014.04.002.

Sarmah, A.K., Meyer, M.T., Boxall, A.B.A., 2006. A global perspective on the use, sales, exposure pathways, occurrence, fate and effects of veterinary antibiotics (VAs) in the environment. Chemosphere 65 (5), 725-759. http://dx.doi.org/10.1016 | j.chemosphere.2006.03.026.

Shi, Y., Gao, L., Li, W., Liu, J., Cai, Y., 2012. Investigation of fluoroquinolones, sulfonamides and macrolides in long-term wastewater irrigation soil in Tianjin, China. B Environ. Contam. Tox 89 (4), 857-861. http://dx.doi.org/10.1007 s00128-012-0761-1.

Tolls, J., 2001. Sorption of veterinary pharmaceuticals in soils: a review. Environ. Sci. Technol. 35 (17), 3397-3406. http://dx.doi.org/10.1021/es0003021.

Wei, R., Ge, F., Chen, M., Huang, S., Wang, R., 2010. Pollution of tetracyclines from livestock and poultry farms in aquatic environment in Jiangsu Province, China. J. Agro-Environ. Sci. 29 (6), 1205-1210 [in Chinese with English abstract].

Yin, C., Zhao, M., Jin, W., Lan, Z., 1993. A multipond system as a protective zone for the management of lakes in China. Hydrobiologia 251, 321-329. http:// dx.doi.org/10.1007/BF00007191.

Zhang, H., Zhang, M., Gu, G., 2008. Residues of tetracyclines in livestock and poultry manures and agricultural soils from north Zhejiang Province. J. Eco. Rural. Environ. 24 (3), 69-73 [in Chinese with English abstract].

Zhang, S., Zhang, F., Liu, X., Wang, Y., Zou, S., He, X., 2005. Determination and analysis on main harmful composition in excrement of scale livestock and poultry feedlots. Plant. Nutr. Fertil. Sci. 11 (6), 822-829 [in Chinese with English abstract].

Zhao, L., Dong, Y., Wang, H., 2010. Residues of veterinary antibiotics in manures from feedlot livestock in eight provinces of China. Sci. Total Environ. 408 (5), 1069-1075. http://dx.doi.org/10.1016/j.scitotenv.2009.11.014.

Zheng, J., 2013. Elimination of Veterinary Antibiotics and Antibiotic Resistance Genes from Swine Wastewater in the Vertical Flow Constructed Wetlands. Northeast Forestry University, pp. 56-63 [in Chinese with English abstract].

Zhou, L., Ying, G., Liu, S., Zhang, R., Lai, H., Chen, Z., Pan, C., 2013. Excretion masses and environmental occurrence of antibiotics in typical swine and dairy cattle farms in China. Sci. Total Environ. 444 (2), 183-195. http://dx.doi.org/10.1016/ j.scitotenv.2012.11.087.

Zhu, J., Snow, D.D., Cassada, D.A., Monson, S.J., Spalding, R.F., 2001. Analysis of oxytetracycline, tetracycline, and chlortetracycline in water using solid-phase extraction and liquid chromatography-tandem mass spectrometry. J. Chromatogr. A 928, 177-186. http://dx.doi.org/10.1016/S0021-9673(01)011396. 